
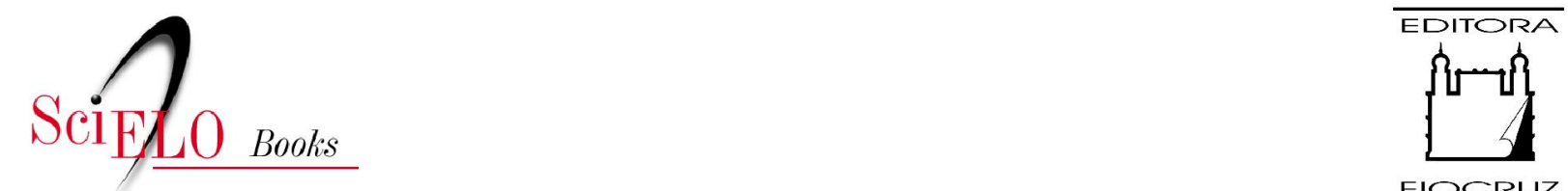

FIOCRUZ

\title{
14. Práticas médicas, toxicomanias e a promoção do exercício da cidadania
}

\author{
Marcelo Santos Cruz
}

\section{SciELO Books / SciELO Livros / SciELO Libros}

CRUZ, MS. Práticas médicas, toxicomanias e a promoção do exercício da cidadania. In:

ACSELRAD, G. org. Avessos do prazer: drogas, Aids e direitos humanos [online]. 2nd ed. rev. and enl. Rio de Janeiro: Editora FIOCRUZ, 2005, pp. 277-288. ISBN: 978-85-7541-536-8. Available from: doi: $10.7476 / 9788575415368$. Also available in ePUB from: $\underline{\text { http://books.scielo.org/id/bgqvf/epub/acselrad-9788575415368.epub }}$

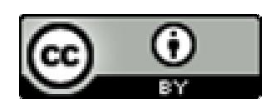

All the contents of this work, except where otherwise noted, is licensed under a Creative Commons Attribution $\underline{4.0 \text { International license. }}$

Todo o conteúdo deste trabalho, exceto quando houver ressalva, é publicado sob a licença Creative Commons Atribição 4.0.

Todo el contenido de esta obra, excepto donde se indique lo contrario, está bajo licencia de la licencia Creative Commons Reconocimento 4.0 . 


\section{Práticas Médicas, Toxicomanias e A Promoção do EXERCício da CIDADANIA}

Marcelo Santos Crug

Desde o século XIX, a questão do uso abusivo de substâncias psicoativas foi assumida pela medicina como um problema médico. Apesar do desenvolvimento de teorias explicativas e de práticas direcionadas ao tratamento dos indivíduos dependentes, a abordagem médica do uso de drogas necessita ser enfocada cuidadosamente, pois está longe de ser consensual. Isso ocorre porque as tentativas de explicar os fenômenos relacionados às toxicomanias por meio dos modelos teóricos que tradicionalmente têm explicado outras formas de adoecer têm produzido aproximações bastante incompletas. Além disso, muitos aspectos do problema, como aqueles ligados, por exemplo, às questões sociais, culturais, legais, jurídicas e outras, fogem do alcance da medicina. E, ainda, porque as práticas propostas por uma visão restrita da medicina, ou seja, por uma visão biologista, têm sido, até o momento, limitadas nos seus resultados. Finalmente, porque não são evidentes os limites entre as incumbências da medicina e as de outras instituições designadas pela sociedade para cuidar das questões relacionadas às toxicomanias. É o caso da interface entre a Justiça e a medicina, foco de importante discussão de âmbito internacional e nacional. Constantemente ocorre que certos problemas sejam vistos ora como questões legais, ora como questões médicas, e esse fato tem conseqüências não apenas na definição das propostas de tratamento, mas principalmente na definição das políticas públicas para a questão.

O papel da medicina na abordagem das toxicomanias está, portanto, em discussão, e há formas diversas de conceber a participação do médico no enfoque desses problemas. Ao mesmo tempo vivemos em meio ao embate de forças sociais, e os direitos dos cidadãos são constantemente ameaçados. Nesse confronto, o uso de drogas e as formas de lidar com o assunto são elemen- 
tos poderosos que se entrelaçam com os demais no jogo social. É importante que as ações médicas sejam discutidas para se assegurar que a participação do médico e a das instituições de saúde sejam coerentes com propostas democráticas, dirigidas para o pleno desenvolvimento do exercício da cidadania.

Nosso objetivo aqui é expor experiências de práticas médicas comprometidas com o exercício da cidadania. Esta descrição inclui a relação entre o campo da medicina, aí incluídos o saber e as práticas médicas e os demais campos envolvidos, com seus próprios saberes e práticas. Para tal, descreveremos inicialmente o desenvolvimento de concepções médicas dominantes, discutindo como diferentes formas de compreender a natureza da dependência de drogas são articuladas a práticas diferentes. Pretendemos enfatizar o cuidado necessário para se evitar que a atuação médica seja utilizada como instrumento de controle social.

\section{Modelos Conceituais Dominantes sobre AS TOXICOMANIAS}

As divergências entre os modos de compreender o uso abusivo de substâncias psicoativas envolvem tanto aspectos ligados ao atendimento de cada paciente como questões de alcance muito mais amplo, como a definição das políticas públicas nessa área. Esses aspectos micro (enfoque particular do usuário de drogas) e macro (determinação de ações gerais, como a repressão, a assistência e a prevenção) não têm relação de causa e efeito, mas são resultado de uma mesma concepção (Stein, 1990).

De forma sistemática, pode-se descrever os modelos sobre o uso abusivo de drogas como: modelo jurídico-moral, modelo médico, modelo psicossocial e modelo sociocultural (Nowlis, 1975). O modelo jurídicomoral objetiva resolver o problema do uso de drogas impedindo o acesso e a utilização de substâncias pela repressão ao tráfico e ao uso. Separa drogas lícitas (como o álcool e a nicotina) das ilícitas e se preocupa com o controle das últimas. Essa separação não encontra justificativa no conhecimento médico, se apóia na tradição e na divulgação social de idéias que podem ser puramente preconceituosas. Apesar do emprego de recursos astronômicos e resultados medíocres, o modelo jurídico-moral encontra força nas parcelas mais conservadoras da sociedade e é freqüentemente utilizado como forma de controle social.

O modelo médico tenta estender para esse campo paradigmas que tiveram sucesso na explicação de outras formas de adoecer. No caso das toxi- 
comanias, as tentativas de explicação se ligam à ação das drogas no sistema nervoso central, provocando quadros como a intoxicação ${ }^{1}$ e a abstinência. ${ }^{2}$ Nesse modelo, a ação das drogas é relacionada de forma menos consistente ao comportamento do indivíduo, quando não está sob efeito da substância. De forma indevida, outro paradigma médico é associado, com freqüência, às toxicomanias: o das doenças infecciosas. Segundo esse modelo, o indivíduo vulnerável se torna doente quando o agente nocivo entra no seu organismo e o mal pode ser transmitido adiante, provocando epidemias. As terapias comportamentais se encaixam com facilidade no modelo médico, e embora tenha havido entusiasmo recente pelo desenvolvimento de novas técnicas, estas também têm seus limites, da mesma forma que as demais práticas propostas. Tanto quanto o modelo jurídico, o modelo médico coloca a ênfase na substância, e não no indivíduo ou nas circunstâncias sociais. Há avanços interessantes no desenvolvimento de estratégias que incluem o uso de fármacos no tratamento e de pesquisas na área de neurobiologia, mas esses progressos não indicam que as demais dimensões do problema percam sua importância no futuro.

Como veremos adiante de forma mais detalhada, o modelo psicossocial cogita o uso de drogas como uma forma de lidar com conflitos ligados à história de vida da pessoa. Realça a relação do indivíduo com a substância e com as outras pessoas. O modelo sociocultural sugere que as sociedades humanas sempre utilizaram substâncias psicoativas e que cada grupo social define seus usos e suas interdições. Tais interdições são também historicamente relacionadas ao uso de substâncias psicoativas, o que é freqüentemente esquecido na discussão atual sobre o estatuto legal das práticas relacionadas ao consumo de drogas.

Esses modelos, em geral, não são adotados isoladamente, até porque cada um deles, por si só, não é suficiente para a compreensão dos fenômenos e muito menos propõe formas suficientes para a sua abordagem. No entanto, algumas aproximações são comuns, como a do modelo jurídico-moral com o modelo médico, de um lado, e a do psicossocial com o sociocultural, de outro.

Interessa discutir aqui as abordagens terapêuticas; assim, retomaremos a discussão sobre o modelo médico e o psicossocial. De modo geral, nenhuma forma de abordagem pode reduzir, de forma simplista, questão tão complexa. Ao contrário, a assistência, o ensino e a pesquisa sobre o uso de drogas devem

\footnotetext{
Manifestações psíquicas e comportamentais associadas ao efeito da substância.

2 Manifestações psíquicas e comportamentais que ocorrem quando o uso da substância é bruscamente interrompido ou reduzido.
} 
refletir essa complexidade e sugerir interrogações que ampliem o conhecimento em direção a cada um dos aspectos envolvidos, de forma articulada, tornando possível o desenvolvimento de práticas em que os recursos adequados desses modelos sejam úteis.

\section{EVolução do Conceito de DependênCIA}

Foi somente a partir do século passado que o uso abusivo de substâncias psicoativas passou a ser definido como um problema médico. Berridge (1994), historiadora do assunto, afirma que foi Thomas Trotter quem cunhou o conceito de "adicção", 3 afirmando que o "hábito da embriaguez era uma doença da mente" (grifo nosso). Nos países de língua inglesa, passou-se a usar o termo addiction, que foi traduzido para o português como 'vício'. A questão, que antes tinha explicações morais ou religiosas, passou a ser vista como uma questão médica. Nessa época, o uso do álcool e da morfina foi explicado pelas teorias da hereditariedade e da degeneração, como se fazia, então, para outras formas de adoecer psíquico. Berridge chamou a atenção para o fato de que a nova definição do uso do álcool como doença poderia pressupor um tratamento mais humanitário, mas o tratamento proposto - o confinamento compulsório - pouco diferia da abordagem punitiva.

No início do século XX, o movimento de Higiene Social se utilizava ainda das idéias de hereditariedade e degeneração para propor intervenções sobre as pessoas que usavam abusivamente o álcool ou outras drogas. Também foi a partir do início do século que o surgimento da psicanálise veio se contrapor às idéias que sustentavam ser o uso de drogas algo explicável exclusivamente por seus aspectos biológicos.

Após a Segunda Guerra Mundial, o movimento da Higiene Social perdeu força, sendo substituído por uma nova saúde pública que dá ênfase aos cuidados primários, ao tipo de vida individual, ao planejamento de saúde e aos indicadores de saúde da área. É importante acompanhar as definições dos termos utilizados nessa área, pois elas refletem formas de conceber

3 Embora seja utilizada freqüentemente em textos em português, o dicionário Aurélio não inclui essa palavra. Em latim a palavra addictum designava aquele que na República Romana tornava-se escravo para pagar uma dívida, por não dispor de outros recursos. Addictum era aquele que havia perdido sua identidade, assumindo uma outra identidade imprópria como única maneira possível de saldar sua dívida. Para ser alguma coisa devia aceitar não ser ninguém (Bento, 1986). 
as toxicomanias. Na década de 50, a Organização Mundial da Saúde (OMS) passou a ter um papel destacado no âmbito internacional na abordagem das questões relativas ao uso de drogas. Nessa época, uma Comissão de Peritos da OMS definiu o que seriam 'vício' e 'hábito' (Grinspoon \& Balakar, 1976). Depois, para evitar o envolvimento de aspectos morais e ideológicos, a OMS abandonou o termo 'vício' e passou a se referir a 'dependência'. ${ }^{4}$ Em 1969, quando a OMS definiu que havia dependência psicológica de cocaína, abriu caminho para a separação entre 'dependência física' e 'dependência psíquica' (Grinspoon \& Balakar, 1976).

Morgado (1985) criticou vários aspectos das formulações da OMS, entre eles a inconsistência da relevância dada à dependência física. Lembrou o relato de Robins, Davis e Nurco (1974) sobre soldados americanos que usaram heroína no Vietnã e que abandonaram seu uso ao retornar da guerra antes mesmo de receberem qualquer tratamento, mostrando que as explicações fisiológicas não são suficientes. Morgado levantou, também, a questão da dependência ligada a outros objetos (como comida ou jogos), em que fica patente que há outros aspectos envolvidos.

A partir da década de 80 , as classificações diagnósticas desenvolvidas pela Associação Psiquiátrica Americana (APA) têm influenciado diretamente a conceituação dos fenômenos relativos ao uso de drogas. Até essa época, a

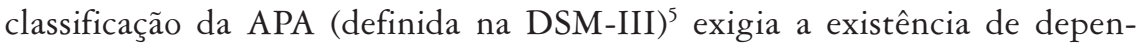
dência física para o diagnóstico de dependência. As classificações que se seguiram utilizaram uma definição mais ampla de dependência, com dimensões biológica, social e comportamental, e cujo aspecto central seria a perda do controle sobre o uso da substância. Essas classificações influenciaram diretamente a Classificação Internacional das Doenças da OMS que, na sua décima edição (CID-10), incluiu critérios bastante semelhantes aos utilizados pela Associação Psiquiátrica Americana. O importante a assinalar é que, apesar de uma tendência à valorização dos aspectos biológicos observada na psiquiatria da última década, a conceituação de dependência evoluiu de uma definição puramente biológica para uma que envolve as dimensões psicológicas e sociais da questão.

Atualmente, a influência da psiquiatria americana não se restringe à conceituação. Em relação às toxicomanias, como em outras áreas da psiquiatria, o desenvolvimento do conhecimento nos Estados Unidos da América é

\footnotetext{
4 Dependência também tem origem no latim pendere, que significa estar pendurado, suspenso, estar na expectativa, absorto, ter os olhos fixos em (Faria, 1967).

5 DSM-III é a sigla que designa a terceira edição do Manual Estatístico e Diagnóstico da APA (1984).
} 
rapidamente difundido entre os profissionais da saúde mental no Brasil. Algumas formas de abordagem utilizadas amplamente no nosso país, como os grupos de mútua ajuda (Narcóticos Anônimos - N. A. - e Alcoólicos Anônimos - A. A.), o método Minnesota ${ }^{6}$ e a ênfase nos aspectos comportamentais e biológicos do uso abusivo de drogas, tiveram origem ou são dominantes entre os norte-americanos.

Mesmo entre o norte-americanos alguns aspectos desse modelo são criticados. Stein (1990), por exemplo, afirma que ele impede a individualização e a implicação particular de cada paciente, já que produz prescrições gerais como se todos os usuários de drogas fossem iguais. Esse autor sugere que a associação de uma compreensão médica restritiva com técnicas de modulação de comportamento tem funções específicas de controle social.

\section{A ExperiênCIA de SERVIÇOS EsPeCIALIZAdos NA ASSISTÊNCIA A USUÁRIOS DE DROGAS NO BRASIL}

A implementação de serviços de assistência a usuários de álcool e outras drogas no Brasil não acompanhou, nas décadas de 80 e 90, o crescimento dos problemas relacionados a este uso. Houve um atraso na atenção dos serviços públicos federais, estaduais e municipais para lidar com essa demanda. No entanto, desde a década de 80 instituições especializadas como o Nepad, o Cetad, o CMT, o CPTT, o Proad, o Instituto Raid e Cordato ${ }^{7}$ foram criadas sob a supervisão do professor Claude Olievenstein, que dirigiu o Centre Médical Marmottan, instituição francesa distinguida por sua atuação na assistência e no desenvolvimento de conhecimento no campo das toxicomanias. As atividades desenvolvidas nesses centros têm como eixo a compreensão de que o uso abusivo de drogas é um fenômeno que envolve várias dimensões, incluindo seus aspectos biológicos, psicológicos e socioculturais.

Em 1996, técnicos e alunos do Instituto de Psiquiatria (Ipub) da Universidade Federal do Rio de Janeiro criaram o Projad (Programa de Estudos e Assistência ao Uso Indevido de Drogas) (Cruz, 1999). Para o Projad, levamos a proposta que conhecemos no Nepad, onde, no atendimento a usuários de drogas e seus familiares, são privilegiadas formas de tratamento que promo-

6 Método que prescreve 12 passos como etapas a serem cumpridas por aquele que deseja abandonar o uso de drogas.

7 Nepad (Núcleo de Estudos e Atenção ao Uso de Drogas da Uerj), Cetad, CMT, CPTT, Proad, Instituto Raid e Cordato são outras instituições especializadas em geral ligadas a universidades, criadas respectivamente em Salvador, Belo Horizonte, Vitória, São Paulo, Recife e Brasília. 
vam o desenvolvimento de modos mais satisfatórios de relação consigo mesmo e com os outros. Dessa forma, o recurso ao uso da substância deixa de ter a função anteriormente utilizada. Essa proposta é coerente com a idéia de que indivíduos que estabelecem relações de dependência com substâncias o fazem porque nelas encontram a resolução temporária de motivações inconscientes. Outras formas de tratamento se associam à psicoterapia, que tem o papel essencial de tornar possível o encontro do indivíduo com aspectos anteriormente inacessíveis ao seu consciente. Tal encontro possibilita que o indivíduo ultrapasse impasses existenciais, vá além das repetições inconscientes de comportamentos que impedem o desenvolvimento de sua maturidade e autonomia e permite que ele expanda o seu repertório de recursos para enfrentar as vicissitudes do dia-a-dia.

Esse encontro, muitas vezes lento e entremeado por idas e vindas, encontra suporte no terapeuta que sustenta o desejo do paciente de mudar. Quando digo que o terapeuta suporta e sustenta, importa destacar que, nesse processo, a participação do paciente é essencial e que também é fundamental, nesse momento, que seja estimulada a responsabilização do paciente por seu destino.

Mas, em geral, inicialmente, o paciente não dirige esse desejo de mudança que sustenta o processo psicoterápico. Quase invariavelmente, os pacientes que procuram o tratamento solicitam ajuda em relação ao seu uso abusivo de drogas e trazem expectativas fantasiosas de tratamentos mágicos que os livrem das drogas. Muitos esperam a prescrição de comportamentos a serem seguidos. É comum que, à chegada, os pacientes depositem nos terapeutas suas expectativas de cura, colocando-se como receptores passivos do tratamento imaginado. Evidentemente, esse pedido de ajuda sincero e, muitas vezes, desesperado é acolhido, mas com o cuidado de não reforçar expectativas fantasiosas. Os diversos recursos terapêuticos da instituição (psicoterapia individual ou em grupo, psicofarmacoterapia, atendimento a familiar co-dependente, atendimento à família, oficinas terapêuticas e internação) são indicados de forma individualizada para cada caso. A técnica da entrevista motivacional tem sido utilizada no Projad para pacientes em grupo, como um recurso interessante para facilitar a vinculação dos pacientes ao tratamento. Quando os pacientes iniciam o atendimento psicoterápico, em geral, durante muitas sessões falam principalmente de seus problemas com as drogas. Pouco a pouco, com o contato com o terapeuta vão surgindo outras questões e tornando-se mais claro de que forma a droga tem sido usada para cumprir determinadas funções inconscientes. 
Paralelamente à psicoterapia individual ou em grupo, em muitos casos se associam a terapia de um co-dependente (em geral, mãe ou esposa), terapia de família e oficinas terapêuticas. Essas formas de tratamento vão permitir que aconteçam mudanças intrapsíquicas e na interação interpessoal nas famílias dos usuários de drogas. As modificações de posturas, de formas de agir, o encontro de modos mais satisfatórios de viver ocorrem, freqüentemente, em paralelo na família e naquele que usa drogas, através de influências mútuas e positivas.

O papel do médico é essencial para referendar a importância da psicoterapia no processo de tratamento. Outras funções fundamentais do atendimento médico incluem o exame psiquiátrico que permite a identificação de outros transtornos psiquiátricos que freqüentemente se associam à dependência de drogas. Esses quadros associados, ou co-morbidades, como quadros depressivos, ansiosos, esquizofrênicos ou outros, exigem tratamento específico sem o qual o tratamento da dependência de drogas pode ficar inviabilizado.

O tratamento psicofarmacológico é utilizado quando são identificados quadros associados com a toxicomania. Também podem ser indicados fármacos para quadros de intoxicação, abstinência e para reduzir o risco de recaída. Também nesses casos as indicações são individualizadas. Sabe-se que muitas vezes a associação entre psicoterapia e o uso de psicofármacos facilita a vinculação ao tratamento. As medicações auxiliam que se ultrapassem as fases de maior depressão e/ou ansiedade, possibilitando o estabelecimento de vínculo psicoterápico. É evidente que há que se ter o cuidado de priorizar o uso de medicações que não provoquem dependência, para se evitar a troca de uma droga por outra. Os quadros de abstinência podem exigir cuidados especiais.

Em situações em que o paciente não consegue interromper o uso compulsivo, apesar de seu interesse e esforço, pode-se lançar mão de encaminhamento para internação em clínicas públicas especializadas. As instituições especializadas estão adequadas, atualmente, ao modelo proposto pelo Ministério da Saúde de articulação em rede, entre si e com as demais unidades de saúde, de acordo com a reforma psiquiátrica brasileira.

Em todas essas circunstâncias, o trabalho médico é indispensável e o bom uso dos recursos pode ser decisivo para o curso do tratamento. Mas, é importante que ele seja visto pelo médico e pelos demais como um recurso valioso entre outros também indispensáveis. Esse cuidado é necessário para que se evite a concepção errônea de que o enfoque biológico da situação será suficiente. Além disso, é preciso que os recursos terapêuticos (médicos ou outros) sejam usados sem que se retire do paciente sua responsabilidade sobre o tratamento. 


\section{Atendimento Médico a Usuários de DROGAS E INTERAÇÃO PSICOSSOCIAL}

As maiores dificuldades do atendimento médico aos dependentes de drogas encontram-se justamente nos aspectos contemplados de forma menos satisfatória na formação profissional. No que tange aos aspectos diagnósticos e psicofarmacoterápicos, há necessidade de atualização constante, já que nessa área tem havido intensa produção científica. Mas, há necessidade de aperfeiçoar a capacitação, principalmente, nos aspectos que envolvem questões de interação psicossocial. Assim, as ações médicas como prescrição de medicamentos, indicação ou não de internação, encaminhamento para outras formas de tratamento e a interação com outras pessoas interessadas no tratamento do paciente (como a família, o empregador, a Justiça etc.) devem levar em consideração sempre suas conseqüências médicas e psicossociais.

Entre as conseqüências indesejáveis de uma abordagem médica reducionista das toxicomanias está a de acentuar a não implicação do paciente nas suas escolhas. Foi um avanço a mudança da concepção sobre a dependência de substâncias psicoativas, antes considerada uma questão moral, e que passou a ser vista como um problema médico. Mas, é preciso ir além, considerando as toxicomanias problemas de saúde, incluindo seus aspectos médicos, psicodinâmicos e socioculturais. Quando as toxicomanias passaram a ser encaradas como um problema médico, passaram a ser vistas como uma doença como outra qualquer. Essa concepção coloca em marcha formas de pensar ou modelos bastante arraigados na sociedade em geral e mesmo nos médicos. O modelo de doença inclui, entre seus constituintes, a idéia de inexistência ou de um forte abrandamento da responsabilidade daquele que está doente sobre o que lhe acontece. E envolve a modificação do papel social, daquele que adoece, que passa de uma posição de autonomia e controle sobre si e seu destino para uma de dependência e passividade, como ocorre, de maneira geral, com outras formas de adoecer.

As diversas formas de conceber os fenômenos relacionados às toxicomanias devem suas divergências, em grande parte, à ausência de clareza sobre determinados aspectos. Um dos aspectos centrais se refere à possibilidade ou não de o usuário de drogas julgar e se determinar conforme seu julgamento. Parece haver consenso entre aqueles que têm experiência no tratamento de usuários de drogas sobre o fato de que em certas situações há, efetivamente, perda de controle. Exemplos disso ocorrem durante determinadas situações de intoxicação ou abstinência. Mas o consenso termina por aí. Não há indicações 
precisas sobre quando retorna a possibilidade de julgamento e determinação nem sobre o uso de substância, nem sobre outros atos. Se a medicina é instituída pela sociedade para cuidar do usuário quando ele não tem controle sobre si, a utilização do poder médico fora dessas situações é técnica e eticamente questionável. Do ponto de vista técnico, o que se questiona é o fato de que, quando o médico toma para si a responsabilidade por qualquer decisão do usuário de drogas, este passa a um papel passivo (ou de oposição) no tratamento.

Usuários de drogas que procuram tratamento demonstram dificuldade em perceber de que forma motivações, em geral inconscientes, determinam escolhas de caminhos que levam ao aprofundamento das relações de dependência (com a droga ou com pessoas). Evidenciam essa dificuldade referindose ao uso da substância como algo que lhes acontece: "uso porque sou viciado" ou "uso porque sou doente". E ficam assim justificados não apenas o uso da droga, mas inúmeros outros comportamentos indesejados.

Sem dúvida é pior pensar a questão como moral ("usa porque é semvergonha”), mas há que se ter cuidado para que o modelo de doença não reforce a não implicação do sujeito. Esse reforço pode referendar fantasias de que só a medicação ou o afastamento da substância pelo controle do comportamento ou pela internação serão, por si, suficientes. Em cada um desses casos, essas fantasias se associam à idéia de recebimento passivo de uma ação terapêtica que vem de fora do indivíduo. $\mathrm{E}$, da mesma forma que a responsabilidade pelos atos durante o uso da droga, fica colocada fora do indivíduo a responsabilidade pelas modificações com o tratamento.

Essa concepção reforçada pelo modelo de doença freqüentemente leva a que o usuário deixe por conta do médico e da família o desejo do tratamento. $\mathrm{Na}$ ambigüidade que apresenta entre querer e não querer parar de usar drogas, a idéia de impotência diante das drogas pode levar o paciente a não lutar, não procurar compreender o que se passa com ele e não acreditar na possibilidade de mudar.

Há, ainda, outras conseqüências desastrosas da compreensão das toxicomanias como um transtorno exclusivamente biológico e das tentativas de tratá-lo sem a implicação do paciente. Psiquiatras menos informados podem empregar tratamentos descabidos como antipsicóticos, eletroconvulsoterapia e prolongadas internações compulsórias. Instituições obscuras se utilizam de práticas que se assemelham aos tratamentos morais dos séculos passados. Evidentemente, nesse curso sai-se do terreno do que é tecnicamente questionável e vai-se em direção ao que é eticamente inaceitável.

Se as conseqüências de uma prática que conceba as toxicomanias em sua dimensão biológica são danosas no trato do usuário, o mesmo se pode 
dizer quanto às conseqüências das ações dirigidas à coletividade. Essas incluem tentativas de prevenção pelo amedrontamento, a utilização de exames laboratoriais que favorecem a discriminação profissional e a normatização rígida dos comportamentos.

No trabalho institucional, todo cuidado é pouco para se evitar o uso do poder médico como forma de controle social. Isso se manifesta, por exemplo, nos pronunciamentos sobre a questão nos meios de comunicação, na orientação sobre estratégias de prevenção, na interação com a administração de empresas sobre o uso de exames para rastreamento do uso de drogas, nas respostas às solicitações da Justiça etc. Nos serviços de assistência, deve haver o maior cuidado sobre solicitações externas de informações sobre os pacientes ou seu tratamento. Isso inclui instituições, empresas e a família. Em casos em que o próprio paciente solicita esse contato, só se pode prestar informações a terceiros depois de se ter discutido com ele as possíveis conseqüências disso. Uma exceção é o caso do atendimento a adolescentes, quando a concordância da família é indispensável.

No que se refere à interface entre a saúde e a Justiça na abordagem dos problemas relacionados ao uso de drogas, é necessário ampliar a discussão, incluindo os parceiros do Judiciário que privilegiam uma visão democrática e de respeito aos direitos de cidadania. Nesse diálogo deve-se questionar a concepção jurídico-moral do uso de drogas e a proposta de lidar com esses problemas apenas pela via da repressão da oferta e uso de drogas (Karam, 2003). Além disso, é importante assegurar que mesmo nos encaminhamentos judiciários para tratamento, as decisões como 'quem deve ser tratado' e 'como' devem ser tomadas pelas equipes de saúde, e não por profissionais do Judiciário que não são capacitados nem instituídos pela sociedade para tal.

\section{CONCLUSÃO}

É fundamental, então, a participação do médico no debate social sobre as questões relacionadas ao uso de substâncias psicoativas, para que se evite, de um lado, a omissão e, de outro, as práticas dirigidas para o controle social. A função social do médico vai além do atendimento aos pacientes e se estende pelas diversas formas de interação com outros elementos da sociedade. Uma série de progressos tem aumentado o repertório de recursos médicos que são úteis no tratamento de usuários de drogas. É importante que a eles se somem outros que promovam o crescimento do indivíduo e de sua família em dire- 
ção ao maior desenvolvimento de sua saúde e autonomia. Serviços como o Nepad, o Projad e outros têm tido papel importante na prática assistencial e no desenvolvimento do conhecimento sobre as toxicomanias. As universidades têm uma função essencial na criação do saber, na interlocução com outros setores da sociedade e na formação de profissionais capacitados para lidar adequadamente com os problemas trazidos pelo uso abusivo de drogas.

\section{REFERÊNCIAS BIBLIOGRÁFICAS}

ASOCIACIÓN PSIQUIATRICA AMERICANA. DSM-III. Manual Diagnóstico e Estatístico de los Transtornos Mentales. Trad. espanhol Miral, M. V et al. Barcelona: Masson, 1984.

BENTO, V. E. S. Os Componentes Psicopatológicos das Toxicomanias. Curitiba: Editora do Autor, 1986.

BERRIDGE, V. Dependência: história dos conceitos e teorias. In: EDWARDS, G. \& LADER, M. (Eds.) A Natureza da Dependência de Drogas. Porto Alegre: Artes Médicas, 1994.

CRUZ, M. S. et al. Criação de serviço de atendimento a usuários de drogas em ambulatório do Instituto de Psiquiatria da UFRJ: experiência de dois anos. Informação Psiquiátrica 18(1):17-22, 1999.

FARIA, E. Dicionário Escolar Latino-Português. Rio de Janeiro: Campanha Nacional de Material de Ensino, 1967.

GRINSPOON, L. \& BALAKAR, J. B. Cocaine, a Drug and its Social Evolution. 1.ed. New York: Basic Books, 1976.

KARAM, M. L. Redução de danos, ética e lei: os danos da política proibicionista e as alternativas compromissadas com a dignidade do indivíduo. In: SAMPAIO, C. M. A. \& CAMPOS, M. A. (Orgs.) Drogas, Dignidade e Inclusão Social: a lei e a prática de redução de danos. Rio de Janeiro: Associação Brasileira de Redução de Danos, 2003.

MORGADO, A. F. O incansável adiamento do conceito de dependência, inclusive de drogas. Revista da Associação Brasileira de Psiquiatria, 7(26):92-102, 1985.

NOWLIS, H. Introdução e visão de conjunto. In: A Verdade sobre as Drogas: a Unesco e seu programa. Rio de Janeiro: Instituto Brasileiro de Educação, Ciência e Cultura (Ibecc), Universidade do Estado do Rio de Janeiro, 1975.

ORGANIZAÇÃO MUNDIAL DA SAÚDE. Classificação de Transtornos Mentais e de Comportamento da CID-10: Descrições Clínicas e Diretrizes Diagnósticas. Trad. Dorgival Caetano. 1.ed. Porto Alegre: Artes Médicas, 1993.

ROBINS, L. N.; DAVIS, D. H.; NURCO, D. N. How permanent was Vietnam drug addiction? American Journal of Public Health, 64(supl.):38-43, 1974.

STEIN, H. F. In what systems do alcohol/chemical addictions make sense? Clinical ideologies and practices as cultural metaphors. Social Sciences Medicine, 30(9):987-1.000, 1990. 